McGregor, J. F. (1954). J. gen. Microbiol. 11, 52-56.

\title{
Nuclear Division and the Life Gycle in a Streptomyces sp.
}

\author{
By J. F. McGREGOR \\ Atomic Energy of Canada Limited, Chalk River, Ontario
}

SUMMARY: The life cycle of a Streptomyces sp. was studied by the Robinow HCl-Giemsa method of nuclear staining, and is described in the following manner: (1) initial nuclear division phase; (2) primary mycelium; (3) secondary mycelium (including aerial); (4) the formation of spores. It was observed that the method of nuclear division in the ungerminated spores closely resembled mitosis of certain higher organisms and lower plants, by the appearance of two terminal bodies whose behaviour was similar to mitotic centrosomes. The primary mycelium developed after the initial nuclear division phase and produced side branches, then later gave rise to single swellings in the hyphae. These swellings grew to form large round cells, each of which contained many nuclei. It was from these cells that the secondary mycelium developed, a part of which became aerial and terminated in the form of chains of uninucleate spores.

Recent developments in the cytology of bacteria have brought forth the publication of many photomicrographs in which nuclear configurations have been interpreted as phases in mitosis (Delamater, 1951; Delamater \& Woodburn, 1952; Beutner, 1953). But the demonstration of a mitotic spindle in bacteria has been seriously questioned on the grounds that it is possible to confuse artifacts with mitotic spindles (Bisset, 1953). It is the purpose of this paper to present observations of a nuclear division that closely resembles mitosis in higher organisms and of the life cycle of a Streptomyces sp. whose taxonomic position links the bacteria with the moulds (Henrici, 1947).

In the course of my work on the genetic effects of radiations on a Streptomyces sp., a cytological study was undertaken to determine the time of nuclear division in the germinating spores, and to observe whether the secondary mycelium arose from distinctive 'initial' cells similar to those described in actinomyces by Klieneberger-Nobel (1947). In the streptomyces examined it was observed that the first nuclear division was preceded by the formation of two terminal bodies arranged similarly to those already demonstrated in certain bacteria by Delamater (1951) and who interpreted his observations as a mitotic division mechanism. But in the streptomyces spores the terminal bodies were more readily distinguishable. At a certain stage of growth in the primary mycelium the initial cells were seen to develop from swellings in the hyphae, and not from 'nests' of tangled filaments as was observed by Klieneberger-Nobel (1947) in actinomyces.

\section{MATERIAL AND METHODS}

An organism, a Streptomyces sp. (laboratory strain T12) isolated from the soil by Dr J. W. Rouatt was used. It produces colonies consisting of a primary mycelium with deep orange colour, and a fluffy layer of paler orange secondary or aerial mycelium. 
Spores were grown on M12 agar (asparagine, Bacto peptone, dipotassium phosphate 0.5 g. each; glucose 10 g.; Bacto agar 15 g.; and tap water $1000 \mathrm{ml}$.) for the examination of early stages of colony development; but for examining the later stages of growth liquid cultures were studied since the hyphae began to branch and burrow into agar. For the examination of the early stages an agar block was cut from a 7-day stock culture on M12 medium, and pressed against a new agar plate, moving it over the surface to form an inoculum of diminishing density; the plate was then incubated at $28^{\circ}$. A number of types of liquid culture were tried, but the best results were obtained by incubating the spores in M12 liquid medium between cover-glass and slide. In this manner, micro-colonies grew on the borderline of the air and medium, and were kept flat by the surface of the cover-glass. Mature colony impressions were also made from liquid and solid cultures.

The Robinow (1945) method of nuclear staining was used. This consisted of fixing agar blocks of spores for $2 \mathrm{~min}$. in the vapour of $2 \%$ osmic acid, transferring the spores to albuminized cover-glasses by impression, immersion in mercuric chloride (saturated) for 4 min., hydrolysing in $\mathrm{N}-\mathrm{HCl}$ at $60^{\circ}$ for $8 \mathrm{~min}$., and then staining with Giemsa stain (Gurr's R66, 20 drops in $10 \mathrm{ml}$. phosphate buffer, $\mathrm{pH} \mathrm{7 \cdot 0)}$ for 10-20 min. Permanent mounts were made in Abopon (Delaporte, 1948-9; obtained from Glyco Products Co. Inc., 26 Court St, Brooklyn, N.Y., U.S.A.).

Photomicrographs were made using the following: $(1) \times 95$ Leitz fluorite oil-immersion lens; (2) $\times 10$ hyperplane eyepiece; (3) aplanatic condenser; (4) Köhler illumination; (5) yellow-green filter for contrast; (6) a Leica $35 \mathrm{~mm}$. camera. This optical system gave a flat field without introducing chromatic aberration.

\section{RESULTS}

The streptomyces are a saprophytic group of the Actinomycetales growing in the form of a much-branched mycelium which terminates growth by forming chains of spores on aerial hyphae (Waksman \& Henrici, 1943). This genus has been divided on the basis of the structure of its sporulating hyphae (Bergey's Manual, 1948), but apart from this there is little literature about a regular morphological description of the actinomycetes. Klieneberger-Nobel (1947) described the life cycle of spore-bearing actinomyces under the following headings: (1) primary mycelium; (2) origin of initial cells; (3) secondary mycelium; (4) formation of spores. In the present investigation the species of streptomyces examined will be similarly described but with an additional 'initial nuclear division phase'.

\section{Initial nuclear division phase}

With the Streptomyces sp. studied here, between the time of implanting the spores on agar and germination (3.5 hr.), the form of the spore (Pl. 1, fig. 1) changed from oval to pear-shaped with the blue-coloured nucleus at the broad end of the cell, and a red-coloured structure at the narrow end (Pl. 1, fig. 2). This clearly defined structure will be referred to as the terminal body. 
On further incubation a second terminal body became visible in the broad end of the cell, and then travelled around from the nucleus to alter the shape of the cell so as to form two narrow ends each with a terminal body, and a broad central portion in which the nucleus remained (Pl. 1, figs. 3, 4). At this stage the cell was elongated to 3 or 4 times its previous length, and the terminal bodies had the appearance of being strongly repelled by one another and by the nucleus.

The terminal bodies provided a number of parallels with the centrosomes (Sharp, 1943) of higher organisms in that: (a) before nuclear division occurred a single terminal body appeared followed by a second which may have been formed by division of the first; $(b)$ the terminal bodies diverged until they reached the opposite sides of the nucleus; $(c)$ shortly after this formation the nucleus divided.

With the relation of likeness between the nuclear division of the streptomyces spore and mitotic division of higher organisms the author has defined the nuclear forms observed in the following manner; resting cells-cells with no terminal bodies; prophase cells-cells with only one terminal body; metaphase cells-two terminal bodies, one at either side of the nucleus, the nucleus not visibly divided; anaphase-nucleus visibly divided.

Table 1. Nuclear changes in streptomyces spores

\begin{tabular}{|c|c|c|c|c|c|}
\hline $\begin{array}{c}\text { Time of } \\
\text { observation } \\
\text { (hr.) }\end{array}$ & $\begin{array}{c}\text { Resting } \\
\text { cells* } \\
(\%)\end{array}$ & $\begin{array}{c}\text { Prophase } \\
(\%)\end{array}$ & $\begin{array}{c}\text { Metaphase } \\
(\%)\end{array}$ & $\begin{array}{c}\text { Anaphase } \\
(\%)\end{array}$ & $\begin{array}{l}\text { No. of } \\
\text { cells } \\
\text { counted }\end{array}$ \\
\hline $\mathbf{0}$ & 100 & - & - & - & 500 \\
\hline 1 & $85 \cdot 2$ & $14 \cdot 1$ & 0.7 & - & 141 \\
\hline 2 & $55 \cdot 9$ & $41 \cdot 2$ & $2 \cdot 0$ & - & 143 \\
\hline 3 & 4.7 & $65 \cdot 8$ & $21 \cdot 1$ & $2 \cdot 9$ & 170 \\
\hline
\end{tabular}

The nucleus then dividided into two and one end of the cell lost its pointed appearance (Pl. 1, figs. 5, 6), while the other end formed the germination tube into which one daughter nucleus entered and underwent further division, presumably in the same manner, though this could not be determined precisely because the hyphae stained so faintly that the contents were obscured. Pl. 1, fig. 7 , shows the sequence of changes that occur during the first $3.5 \mathrm{hr}$. of incubation, and Table 1 gives the proportions on the different phases at different times. Pl. 1, figs. 8, 9, show a comparison of the cell morphology at 2 and $3 \mathrm{hr}$.

\section{Primary mycelium}

When the streptomyces spores were incubated for $5.5 \mathrm{hr}$. fine threads were seen branching from the sides of the main hyphae (Pl. 2, fig. 10), which on solid medium burrowed into the agar. At this time sixteen to thirty nuclei might be seen, and at least $90 \%$ of the spores had produced one hypha, and about $5 \%$, two hyphae. Shortly after this time nearly all the spores developed a second hypha. A terminal body was seen to reappear in the original spore, followed by division of the nucleus and the sprouting of the new hypha from the opposite end of the cell. One of the two daughter nuclei migrated in to this 
new hypha and underwent further division, while the spore case was left with a single nucleus. The development of more than two hyphae from the one was spore not observed in the T12 strain of streptomyces used.

After 16-20 hr. of incubation of slide cultures, each strand of mycelium developed a swelling which contained many nuclei (Pl. 2, figs. 11, 12). These swellings grew into large round cells ('initial' cells) of about 4 times the diameter of the spore cell, and some of them were seen attached to the hyphae by short stalks (Pl. 2, fig. 13). After this stage the initial cells presumably broke away from the hyphae, and from them the secondary mycelium developed.

\section{Secondary mycelium}

Each strand of the new mycelium seemed to develop from an aggregation of a nucleus and cytoplasm of the initial cell. The strands grew in a radial pattern, and a number of nuclei with no obvious cell wall around them were seen at the centre (PI. 2, fig. 15). These new hyphae grew in the form of long slender threads which produced fewer side branches than the primary mycelium. A striking feature of the secondary mycelium was that some of the strands were composed of deeply staining cylinders which had a length about 10 times the diameter of a spore; there were non-stainable gaps between the ends of these cylinders (Pl. 2, fig. 17). Other strands were seen as one continuous deeply stained cylinder. The secondary mycelium with these types of strands formed the matted surface of the colony; the strands which became aerial developed stained regions of shorter and more uniform length, and gave rise to the formation of chains of spore nuclei.

\section{Spore formation}

It seemed apparent that the part of the secondary mycelium which became aerial changed from the deeply stained cylindrical forms to forms in which there were segments which stained less densely as though the nuclear substance were condensing (Pl. 2, fig. 16, right arrow). The appearance of these areas marked the beginning of development of a visible chain of spore nuclei (Pl. 2, fig. 16, left arrow), which were later seen in the forms of : rectangular blocks and bodies that were either round or square (Pl. 2, fig. 18). Before the formation of the spores these irregular shapes changed to round nuclei of constant size, uniformly spaced along the strand. Shortly after this stage it was observed that single spores and short chains of spores broke off readily; from this it was inferred that transverse septa between the nuclei had developed.

The author wishes to thank Dr H. B. Newcombe for his criticism of the manuscript, and Mr N. R. Vincent for the preparation of the photographs.

\section{REFERENCES}

Bergey's Manual of Determinative Bacteriology, 6th ed. (1948). Edited by Breed, R. S., Murray, E. D. G. \& Hrtchens, A. P. Baltimore, Md.: The Williams and Wilkins Co.

Beutner, E. H. (1953). The occurrence of mitosis in Bacillus megaterium and its relation to the growth cycle. J. Bact. 65,619 . 
Bisset, K. A. (1953). Criticism of a technique claimed to demonstrate mitotic spindles in bacteria. Stain Tech. 28, 45.

Delamater, E. D. (1951). A staining and dehydrating procedure for the handling of micro-organisms. Stain Tech. 26, 199.

Delamater, E. D. \& Woodburn, M. (1952). Evidence for the occurrence of mitosis in micrococci. J. Bact. 64, 793.

Delaporte, B. (1948-9). Cytology of bacteria. Yearb. Carnegie Instn. 48, 166.

Henrici, A. T. (1947). Molds, Yeasts, Actinomycetes. New York: Wiley and Sons.

KLIeneberger-NobeL, E. (1947). The life cycle of sporing actinomyces as revealed by a study of their structure and septation. J. gen. Microbiol. $1,22$.

Shanp, I. W. (1943). Fundamentals of Cytology. New York: McGraw-Hill Book Co. Inc.

Robinow, C. F. (1945). Addendum to The Bacterial Cell by R. J. Dubos. Harvard University Press.

Waksman, S. A. \& Henrici, A. T. (1943). The nomenclature and classification of the actinomycetes. J. Bact. 46, 337.

\section{EXPLANATION OF PLATES}

Streptomyces sp., stained by $\mathrm{HCl}-$ Giemsa

Plate 1

Figs. 1-7, $\times 2360$; figs. $8,9, \times 1180$

Fig. 1. Spores in the resting stage; nucleus located centrally and terminal bodies absent.

Fig. 2. Spores after $2 \mathrm{hr}$. incubation on agar; terminal bodies visible at the narrow ends of the cells (uppermost part of the photograph).

Fig. 3. Elongated cells with the nucleus remaining at the centre and a terminal body at each end; note cells left of centre and at bottom right, the nucleus has divided and the terminal bodies are disappearing.

Fig. 4. Similar to fig. 3. Note the cell at the extreme left; early germination, terminal bodies absent.

Figs. 5, 6. Cells showing the two halves of the nucleus separating.

Fig. 7. The changes occurring in the cell from the resting stage until germination; $3.5 \mathrm{hr}$. Figs. 8, 9. Comparison of cells after 2 and $3 \mathrm{hr}$. incubation.

\section{Plate 2}

Figs. 10-18, $\times 2360$

Fig. 10. Primary hypha with side branches of mycelium; 7.5 hr. incubation.

Figs. 11, 12. Swellings which develop into 'initial' cells in the primary hyphae; note nuclear shape within the swellings, and the comparison of the nuclear structure of the hyphae to the hypha in fig. 10.

Fig. 13. Initial cell at the end of a short stem of mycelium.

Fig. 14. Ruptured initial cell showing nuclear contents.

Fig. 15. Development of secondary mycelium from initial cell.

Fig. 16. Transition of secondary mycelium to aerial mycelium; arrow at the right pointing to areas which stain less densely; the arrow at the left indicating the formation of a chain of nuclei.

Fig. 17. Secondary mycelium with long deeply stained cylinders showing non-staining areas between the cylinders.

Fig. 18. A strand of aerial mycelium showing the nuclei changing from irregular shapes to a uniform pattern. 
Journal of General Microbiology, Vol. 11, No. 1
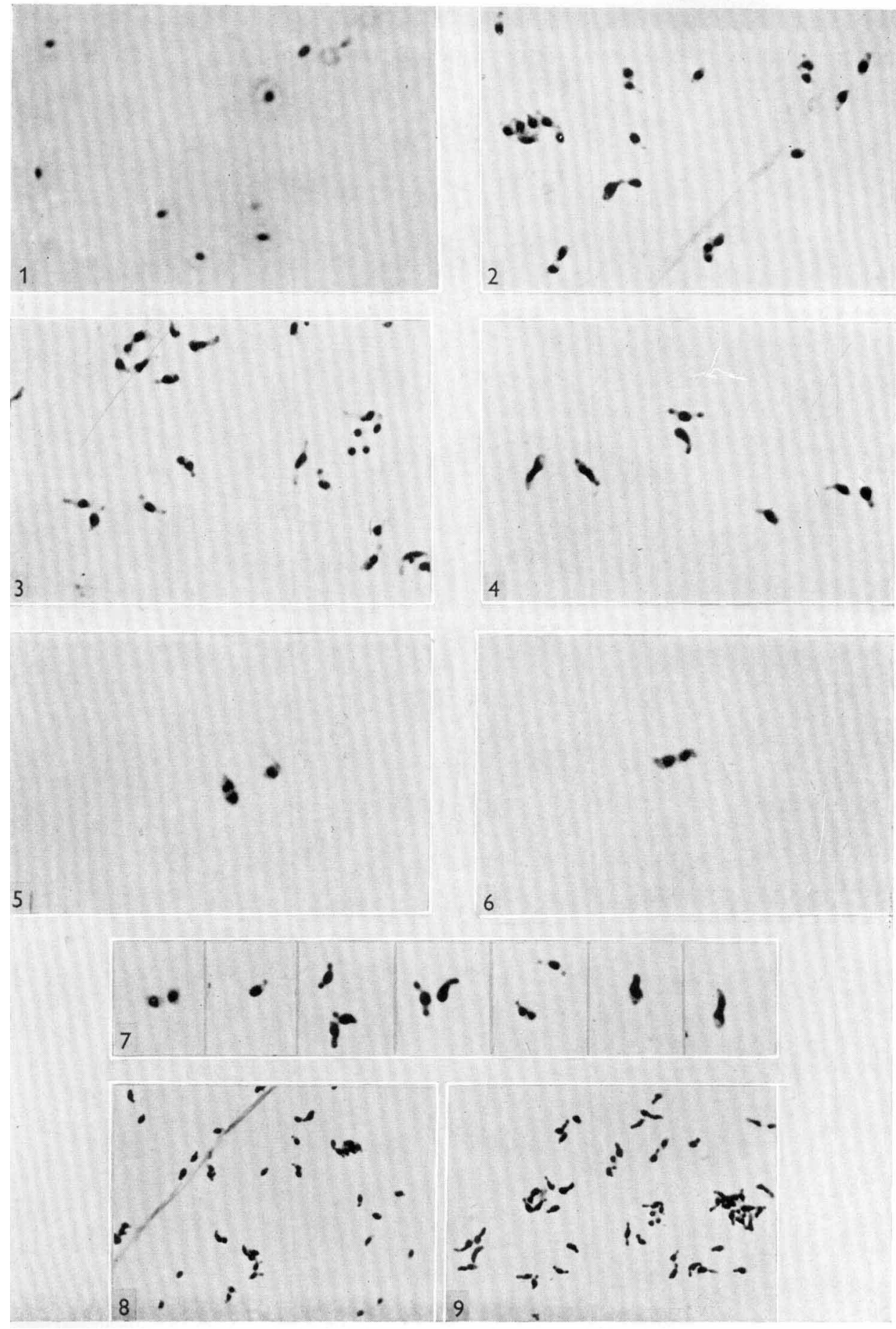

J. F. McGregor-Life cycle in a Streptomyces sp. Plate 1 
Journal of General Microbiology, Vol. 11, No. 1
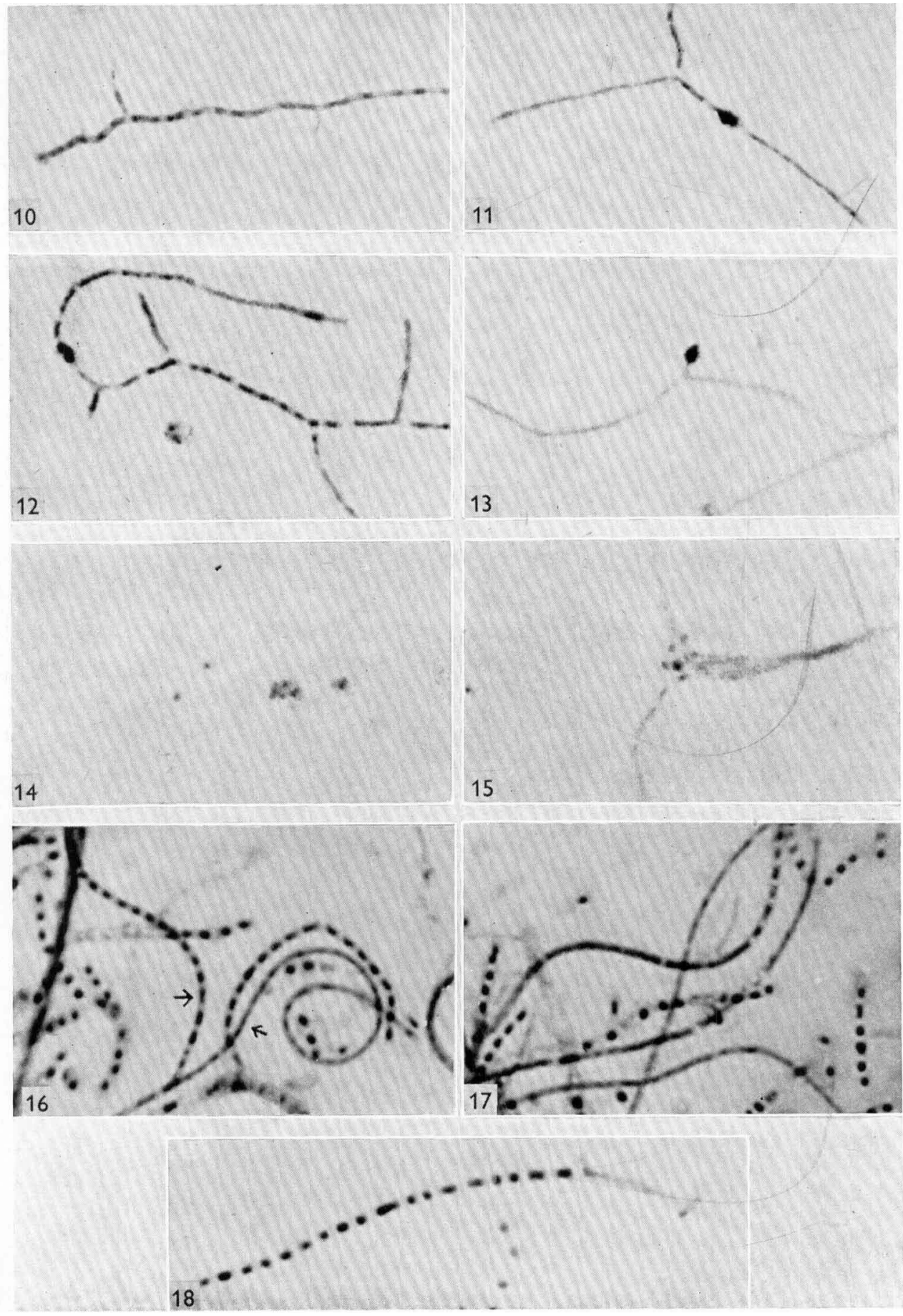

J. F. McGregor-Life cycle in a Streptomyces Sp. Plate 2 